CLINICAL STUDY

\title{
New mechanisms involved in paternal 20q disomy associated with pseudohypoparathyroidism
}

\author{
Eduardo Fernández-Rebollo ${ }^{1, \dagger}$, Beatriz Lecumberri ${ }^{2}$, Intza Garin $^{1,+}$, Javier Arroyo ${ }^{3}$, Ana Bernal-Chico ${ }^{1}$, \\ Fernando Goñi ${ }^{4}$, Rosa Orduña ${ }^{5}$, Spanish PHP Group ${ }^{\S}$, Luis Castaño ${ }^{1,6,7}$ and Guiomar Pérez de Nanclares ${ }^{1,6}$ \\ ${ }^{1}$ Endocrinology and Diabetes Research Group, Molecular Genetics Laboratory, Hospital de Cruces, 48903 Barakaldo, Bizkaia, Spain, ${ }^{2}$ Endocrinology \\ Service, Hospital La Paz, 28046 Madrid, Spain, ${ }^{3}$ Service of Paediatrics, Complejo Hospitalario de Caceres, 10003 Caceres, Spain, ${ }^{4}$ Service of \\ Endocrinology, Hospital de Basurto, 48013 Bilbao, Bizkaia, Spain, ${ }^{5}$ Service of Endocrinology, Hospital Universitario San Cecilio, 18012 Granada, Spain, \\ ${ }^{6}$ Centro de Investigación Biomédica en Red en Enfermedades Raras, 48903 Barakaldo, Bizkaia, Spain and ${ }^{7}$ University of the Basque Country School of \\ Medicine, 48940 Bilbao, Spain \\ (Correspondence should be addressed to G Pérez de Nanclares who is now at Research Unit, Molecular Genetics Laboratory, Hospital Txagorritxu, 01009 \\ Vitoria-Gasteiz, Alava, Spain; Email: gnanclares@osakidetza.net) \\ †(E Fernández-Rebollo is now at Endocrine Unit, Department of Medicine, Massachusetts General Hospital and Harvard Medical School, Boston, \\ Massachusetts, USA) \\ \$(I Garin is now at Research Unit, Molecular Genetics Laboratory, Hospital Txagorritxu, Vitoria-Gasteiz, Spain) \\ $\S$ (Details presented in Acknowledgements section)
}

\begin{abstract}
Purpose: Type I pseudohypoparathyroidism (PHP-I) can be subclassified into Ia and Ib, depending on the presence or absence of Albright's hereditary osteodystrophy's phenotype, diminished $\alpha$-subunit of the stimulatory $G$ protein $\left(\mathrm{G}_{\mathrm{s}} \alpha\right)$ activity and multihormonal resistance. Whereas PHP-Ia is mainly associated with heterozygous inactivating mutations in $\mathrm{G}_{\mathrm{s}} \alpha$-coding exons of GNAS, PHP-Ib is caused by imprinting defects of GNAS. To date, just one patient with PHP and complete paternal uniparental disomy (UPD) has been described.

We sought to identify the underlining molecular defect in twenty patients with parathyroid hormone resistance, hypocalcemia and hyperphosphatemia, and abnormal methylation pattern at GNAS locus.

Methods: Microsatellite typing and comparative genome hybridization were performed for proband and parents.

Results: We describe four patients with partial paternal UPD of chromosome 20 involving pat20qUPD in one case, from 20q13.13-qter in two cases, and pat20p heterodisomy plus interstitial 20q isodisomy in one patient.

Conclusions: These observations demonstrate that mitotic recombination of chromosome 20 can also give rise to UPD and PHP, a situation similar to other imprinting disorders, such as BeckwithWiedemann syndrome or neonatal diabetes.
\end{abstract}

European Journal of Endocrinology 163 953-962

\section{Introduction}

Uniparental disomy (UPD), a nonmendelian form of inheritance, is a condition in which a disomic individual has inherited both copies of a chromosome from one parent only (1) and is a consequence of at least two independent errors occurring during meiosis or immediately after fertilization $(1,2)$ (Figs 1 and 2 respectively). Depending on the identity of the two chromosome homologs, UPD is defined as either heterodisomy (inheritance of both homologs from one parent) or isodisomy (presence of two identical copies of one homolog), and even a mixture of both is possible, reflecting the number and location of meiotic recombinations. The origin of UPD lies in the meiotic nondisjunction events. Specifically, UPD can be due to nondisjunction during meiosis I or II in one parent, leading to a disomic gamete, followed by postzygotic loss of the other parent's chromosome (trisomy rescue), fertilization with a nullisomic gamete for that chromosome from the other parent (gamete complementation), mitotic duplication, and postfertilization error $(1,3-7)$.

Problems associated with UPD are i) placental or even fetal mosaicism normally resulting from trisomy rescue; ii) homozygosity of autosomal recessively inherited mutations; and iii) aberrant expression of imprinted genes. Well-known examples are maternal UPD (15) in $\sim 25-30 \%$ of patients with Prader-Willi syndrome (PWS, MIM 176270); paternal UPD (15) in 2-3\% 


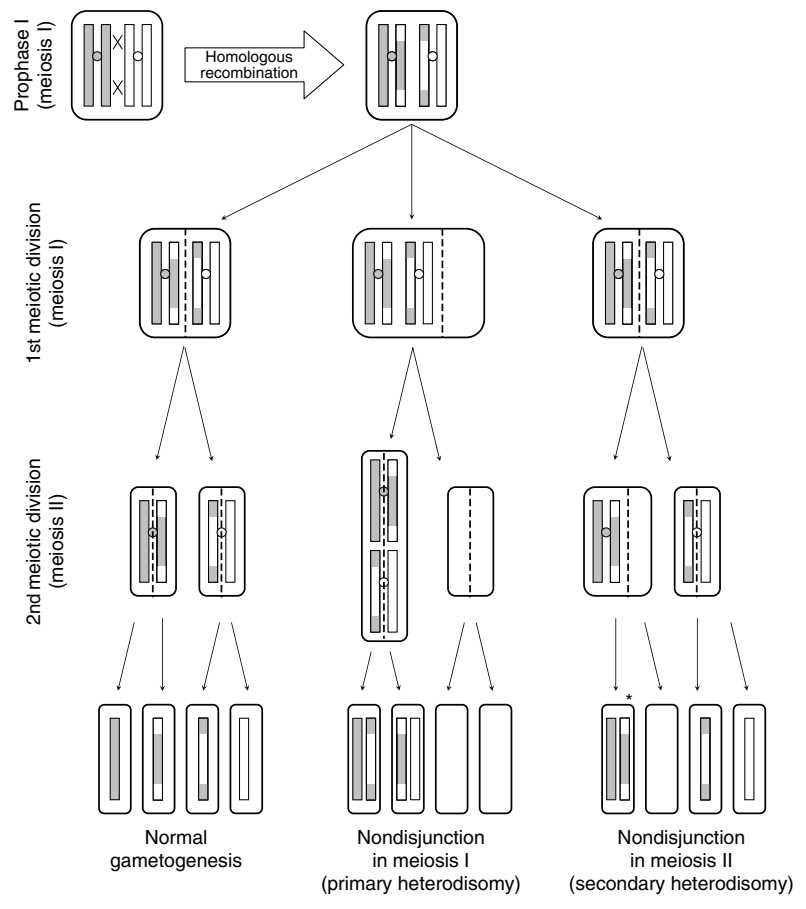

Figure 1 Schematic diagram of the events leading to primary and secondary heterodisomy, compared with normal gametogenesis, for a given pair of autosomes (Adapted from Rivolta et al. (54)). In regular meiosis, each pair of chromosomes is separated during the first meiotic division, whereas the sister chromatids of each chromosome detach during the second meiotic division. If nondisjunction occurs during the first meiotic division, both chromosomes of a pair (or none at all) can be transmitted to a gamete. In contrast, in a nondisjunction event occurring during the second meiotic division, a gamete can have two identical copies of the same chromosome formed from both of its sister chromatids. Vertical hatched lines indicate how chromosomes or chromatids are assorted during cell division. The asterisk represents the putative mechanism that leads the UPD in case 3.

of cases with Angelman syndrome (AS, MIM 105830) (8); transient neonatal diabetes mellitus (paternal UPD6) (9); maternal UPD14 syndrome (10); paternal UPD14 syndrome (11); and Silver-Russell syndrome (maternal UPD7) (12). In addition to these syndromes, more than 100 cases of UPD of other chromosomes have been reported (2).

All these cases describe UPD of a whole chromosome or a whole arm. By contrast, apart from paternal UPD (11) (p15-pter) in 10-20\% of cases with BeckwithWiedemann syndrome (BWS, MIM 130650) (13), UPD of segments of chromosomes or UPD associated with a complex chromosomal rearrangement have rarely been reported (http://www.med.uni-jena.de/fish/sSMC/ OOSTART-UPD.htm). Segmental UPD has been defined as UPD of a part of one chromosome (interstitial or telomeric) together with biparental inheritance of the rest of this pair of chromosomes and a normal karyotype $(14,15)$.

Pseudohypoparathyroidism (PHP; MIM 103580) is a disorder of end-organ resistance that primarily affects the action of the parathyroid hormone (PTH) (16). Genetic defects associated with the various types of PHP involve the $\alpha$-subunit of the stimulatory G protein $\left(G_{s} \alpha\right)$, a signaling protein that is essential for the actions of PTH and many other hormones. Specifically, patients with PHP-Ia have heterozygous inactivating mutations in $\mathrm{G}_{\mathrm{s}} \alpha$-encoding GNAS exons, and they also show resistance to other hormones and a constellation of physical features characteristic of Albright's hereditary osteodystrophy (AHO) (17-19). Patients with AHO features but with no evidence of hormone resistance are said to have pseudopseudohypoparathyroidism (PPHP), and they also carry heterozygous inactivating $\mathrm{G}_{\mathrm{s}} \alpha$ mutations. Maternal inheritance of such a mutation leads to PHP-Ia, i.e. AHO plus hormone resistance, while paternal inheritance of the same mutation leads to PPHP, i.e. AHO only $(18,20,21)$. This imprinted mode of inheritance for hormone resistance can be explained by the predominant maternal expression of $\mathrm{G}_{\mathrm{s}} \alpha$ in certain tissues, including renal proximal tubules (22). Unlike patients with PHP-Ia and PPHP, patients with PHP-Ib show normal $\mathrm{G}_{\mathrm{s}} \alpha$ activity in circulating blood cells and fibroblasts $(21,23,24)$. Nevertheless, a loss of methylation at GNAS exon A/B, which is sometimes combined with epigenetic defects at other GNAS differentially methylated regions, is found in most patients with this disorder $(25,26)$. The familial form of PHP-Ib (AD-PHP-Ib) is typically associated with an isolated loss of methylation at the exon A/B differentially methylated region (DMR) due to maternally inherited microdeletions within STX16 (26-28). In addition, deletions removing the entire NESP55 DMR, located within GNAS, have been identified in some AD-PHP-Ib kindreds, and these affected individuals show loss of all the maternal GNAS imprints (29). Most sporadic PHP-Ib cases also have imprinting abnormalities of GNAS that involve multiple DMRs, but the genetic lesion(s)

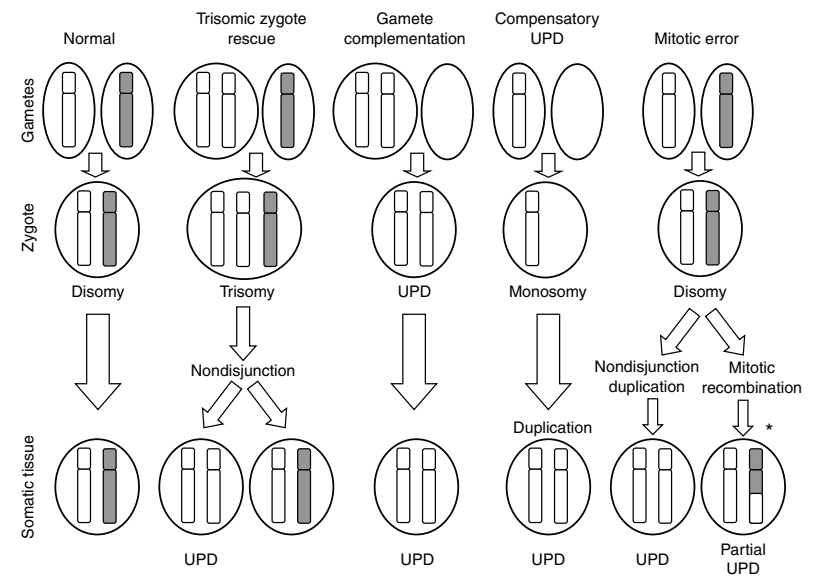

Figure 2 Schematic diagram of the different mechanisms leading to uniparental disomy (UPD) (Adapted from Kotzot (15)). The asterisk represents the putative mechanism that leads the UPD in cases 1 , 2 , and 4. 
responsible, if any, for these imprinting abnormalities remains to be identified (Fig. 3). Paternal isodisomy of chromosome 20q and, thus, a paternal-specific methylation pattern on both alleles have also been shown to be associated with PHP-Ib in two patients $(30,31)$.

Our genetic study was undertaken to identify possible chromosomal alterations in twenty affected patients. We describe new types of mutations consisting of segmental pat20qUPD and hetero/isodisomy for chromosome 20 associated with PHP.

\section{Materials and methods}

\section{Case report}

This study was approved by the appropriate Institutional Review Board, and informed consent was obtained from all human subjects.

Clinical features of each patient are summarized in Table 1 and Supplementary Table 1, see section on supplementary data given at the end of this article.

Case 1 (GSO060) A 32-year-old female patient was admitted to hospital for persistent paresthesia of the four limbs during the preceding week, together with hypertonia of both hands and palpitations. She had previously been diagnosed with extrinsic asthma and had a bone tumor in the left humerus that had been surgically treated. Biochemical studies revealed low calcium and potassium $(2.5 \mathrm{mEq} / \mathrm{l}$, normal values: 3.5-5.1 mEq/l) levels, so she was started on oral calcium, vitamin $\mathrm{D}$, and potassium supplements and after discharge from hospital, the oral calcium dose was increased due to persistence of paresthesia and palpitations. At her last check-up, she remained

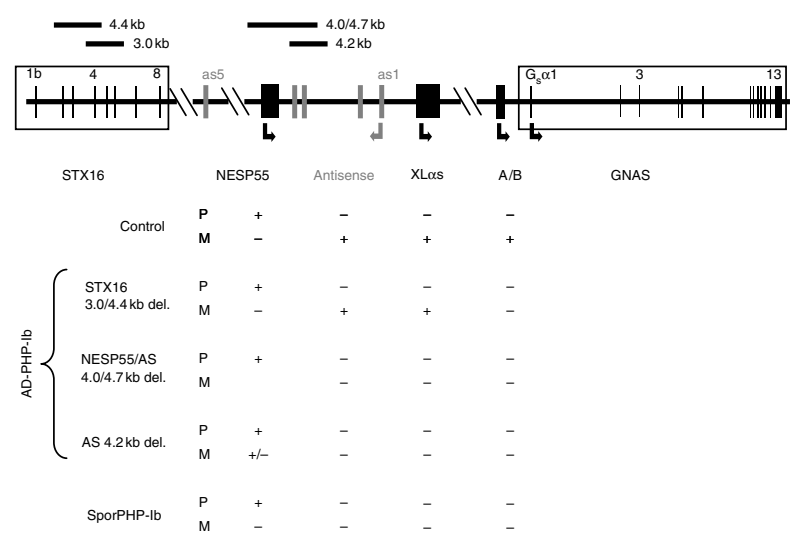

Figure 3 Schematic representation of the GNAS locus. Boxes and connecting lines indicate exons and introns respectively. Promoters of $\mathrm{XL} \alpha \mathrm{S}$, antisense (AS), A/B, and NESP55 transcripts are either maternally $(M)$ or paternally $(P)$ methylated, as indicated by + (methylated CpG islands) and - (unmethylated CpG islands). Arrows indicate origin and sense of transcription. Horizontal bars indicate the deletions identified in patients with AD-PHP-Ib. asymptomatic with a normal thyroid function and PTH levels of $90.8 \mathrm{pg} / \mathrm{ml}$.

Case 2 (GSO064) Clinical features of this patient were described in detail previously (31). Briefly, this was the case of a 25-year-old male patient diagnosed with PHP due to PTH and TSH resistance. He was first studied at the age of 10 months due to obesity, right cryptorchidism, and psychomotor retardation. At the age of 7 years, he was diagnosed with Wilkins epiphyseal dysgenesis and started on thyroxine $\left(\mathrm{T}_{4}\right)$ for his hypothyroidism. Two years later, biochemical tests revealed high serum PTH with hypocalcemia and hyperphosphatemia, leading to the diagnosis of PHP.

On physical examination, it was observed that he had a round face with an ogival palate, clear macrocephaly (+3 s.D.), and no subcutaneous ossifications. He had reached puberty, Tanner Stage 5, and his neurological examination was unremarkable with a negative Chvostek's sign, but mild to moderate cognitive impairment. A cranial computed tomography (CT) scan showed many bilateral and symmetrical supratentorial calcifications in both the globus pallidus and the subcortical area of the frontal lobes, retraction of frontal cortical wrinkles, and a mega cisterna magna.

Case 3 (GSO082) A 5-year-old male patient was admitted to the Accident and Emergency Unit of the hospital due to a high fever that had begun 6 days earlier accompanied by frequent vomiting in the preceding $24 \mathrm{~h}$. He also presented hyporexia, oliguria, malaise, cough and severe laryngeal stridor. At the age of 4 months, he had suffered bronchiolitis, and at the age of 10 months, he had chickenpox, both episodes requiring hospitalization. He was previously studied by his pediatric endocrinologist due to macrosomy (birth weight $4730 \mathrm{~g}$, s.D.: + 3.34) and obesity. Physical examination on admission revealed a facial macular exanthema, bilateral erythematous tympanic membranes, and crepitations in the upper lobe of the left lung. Blood tests showed normal free $\mathrm{T}_{4}$ and TSH, low serum calcium, hyperphosphatemia, magnesium $2.3 \mathrm{mmol} / \mathrm{l}$ (normal range $0.7-1.1 \mathrm{mmol} / \mathrm{l}$ ), and elevated PTH. He was diagnosed with PHP and acute otitis media, treated with i.v. calcium for 3 days and oral calcium and calcitriol from then on, and remained asymptomatic until discharge 8 days later.

Case 4 (GSO090) A 46-year-old male was referred to the endocrinology clinic from the A\&E Unit, that he had attended following a short tonic-clonic seizure. He had previously been studied in the Endocrinology Department for a history of syncopal episodes, with loss of consciousness and sphincter relaxation, tonicclonic convulsions and sporadic seizures, and had been diagnosed with chronic hypocalcemia, hypertension, 
Table 1 Brief summary of clinical data of the index cases at diagnosis.

\begin{tabular}{|c|c|c|c|c|}
\hline & $\begin{array}{l}\text { Case } 1 \\
\text { GS0060 }\end{array}$ & $\begin{array}{l}\text { Case 2 } \\
\text { GS0064 }\end{array}$ & $\begin{array}{l}\text { Case } 3 \\
\text { GS0082 }\end{array}$ & $\begin{array}{l}\text { Case } 4 \\
\text { GS0090 }\end{array}$ \\
\hline Sex & Female & Male & Male & Male \\
\hline Age at diagnosis (years) & 26 & 9 & 5 & 46 \\
\hline Rounded face & No & Yes & Yes & No \\
\hline Weight (kg) & 57 ( -0.1 S.D.) & 57.3 (-0.92 S.D.) & 37.5 (+5.5 s.D.) & 84.8 (+1.5 S.D.) \\
\hline Height (cm) & 154 (-1 S.D.) & 162 (-1.6 S.D.) & 119.5 (p95) & 160 (-2 S.D.) \\
\hline BMI $\left(\mathrm{kg} / \mathrm{m}^{2}\right)$ & 24 & 21.8 & 26.5 & 33.12 \\
\hline \multirow[t]{2}{*}{ Parental height } & \multirow[t]{2}{*}{ NA } & $\mathrm{F}: 167$ & $\mathrm{~F}: 174$ & \multirow[t]{2}{*}{ NA } \\
\hline & & M: 144.5 & M: 170 & \\
\hline Parental age at gestation & $\mathrm{F}: 27$ years & $\mathrm{F}: 31$ years & $\mathrm{F}: 33$ years & NA \\
\hline & $M: 27$ years & $\mathrm{M}: 32$ years & $\mathrm{M}: 33$ years & NA \\
\hline Macrocephaly & No & Yes (>S.D. 3) & Yes (s.D. + 3.3) & No \\
\hline Subcutaneous ossification & No & No & No & NA \\
\hline Intracranial calcifications & No & Yes & No & Yes \\
\hline Brachydactyly & No & No & No & No \\
\hline Cognitive retardation & No & Yes & No & No \\
\hline Calcium (2.2-2.6 mmol/l) & 1.3 & 2.2 & 1.2 & 1.6 \\
\hline Phosphate $(1-1.5 \mathrm{mmol} / \mathrm{l})$ & 1.9 & 2.1 & 2.4 & 1.5 \\
\hline PTH $(15-65 \mathrm{pg} / \mathrm{ml})$ & 601 & 940 & 292.4 & 127.4 \\
\hline Free $\mathrm{T}_{4}(0.7-1.9 \mathrm{ng} / \mathrm{ml})$ & $\mathrm{N}$ & $1.2^{\mathrm{a}}$ & 1.2 & 1.2 \\
\hline TSH $(0.5-5 \mu \mathrm{U} / \mathrm{ml})$ & $\mathrm{N}$ & 2 & 2.8 & 2.9 \\
\hline
\end{tabular}

F, father; M, mother; N, normal values; NA, not available.

${ }^{a}$ The patient was already on levothyroxine treatment at the time of PHP diagnosis.

anxiety depression syndrome, and leukoencephalopathic changes associated with calcium deposits in the brain. He was started on antiepileptic (lamotrigine) and antidepressant (mianserine) drugs, and although he was advised to take oral calcium and vitamin D treatment, he was not taking vitamin $\mathrm{D}$ at the time of his last convulsive episode. A cranial CT scan revealed dense symmetrical calcifications of the basal ganglia, cerebellum, and cerebral parenchyma. Blood tests showed hypocalcemia, hyperphosphatemia with elevated PTH and vitamin D $(25 \mathrm{OH}$ vitamin D) $84.8 \mathrm{nmol} / \mathrm{l}$ (normal values: 20-100). Oral calcium doses were increased, and vitamin $\mathrm{D}$ treatment was reintroduced.

\section{Molecular studies}

GNAS sequence and methylation status analysis The Institutional Review Board of the Hospital de Cruces approved the study. Genetic analyses were performed after obtaining informed consent from the patient or parents. Genomic DNA was extracted from peripheral blood leukocytes using a commercial kit, following the manufacturer's instructions (QiaAmp Blood Mini, Qiagen). The thirteen coding exons of GNAS gene were amplified, and both strands of amplicons were sequenced as described previously (32).

Dosage and methylation analyses were carried out by multiplex ligation-dependent probe amplification (MS-MLPA) using the ME031A kit (MRC-Holland, Amsterdam, The Netherlands). The protocol was implemented following the manufacturer's recommendations. Analysis of the MS-MLPA PCR products was performed on an ABI3130XL genetic analyzer and using the GeneMapper software (Applied Biosystems). For the copy number analysis, the data generated was intranormalized by dividing the peak area of each amplification product by the total area of the reference probes only. The ratios were then obtained by dividing the intranormalized probe ratio in a sample by the average intranormalized probe ratio of all reference runs. For the methylation analysis, the intra-normalized peak area of each MS-MLPA probe from the digested sample was divided by the value obtained for the undigested sample.

When partial loss of methylation was identified, methylation quantification was performed by sequencing of subcloned PCR products after bisulfite modification as described (27).

To characterize the chromosome 20 haplotypes, eight polymorphic markers located at $20 \mathrm{p}$ and eighteen microsatellites at 20q were typed by fluorescent PCR.

Illumina $\mathbf{A 6 6 0}$ SNP array The Illumina Human660W-Quad BeadChip was used for all experiments, according to the methods described by the manufacturer. The array includes 657366 markers distributed evenly across the genome, with 14854 markers being located on chromosome 20. GenCall scores $<0.15$ at any locus were considered 'no calls'. Images were analyzed using the Chromosome Viewer tool contained in Beadstudio 3.2 (Illumina, San Diego, CA, USA). The metric used was the $\log R$ ratio which is the $\log$ (base 2) ratio of the observed normalized $R$ value for an SNP divided by the expected normalized $R$ value (33). In addition, an allele frequency analysis was carried out for all SNPs. All genomic positions were based upon NCBI Build 36 (dbSNP version 126). 


\section{Results and discussion}

Since the first clinical case of UPD was reported, in 1988 (34), the presence, location, and extension of UPD has been associated with specific phenotypic features in BWS (OMIM \#130650) (35), AS (OMIM \#105830) (36), Silver-Russell (OMIM \#180860) (37), matUPD14 (10), PWSs (OMIM \#176270) (38), transient neonatal diabetes (OMIM \#601410) (39), and patUPD14 (OMIM \#608149) (40).

UPD for chromosome 20 has been reported previously in a very few cases, namely matUPD, usually associated with growth and psychomotor retardation and dysmorphic features (41-45), and patUPD, reported only in two cases with PHP-Ib $(30,31)$. Despite this, we analyzed many microsatellites across chromosome 20 in twenty patients with PHP due to lack of maternal methylation imprints at the GNAS locus, and in whom allelic loss had been ruled out by MS-MLPA, looking for disomy as a putative cause of the methylation defect (Supplementary Table 1). Four of the patients were suspected of having patUPD, and the characteristics of this disomy were investigated using SNP arrays.

The microsatellite analysis in cases 1 and 4 indicate that they inherited both copies of chromosome 20, one from each progenitor, except for the paternal isodisomic region found on the distal portion of the long arm (Table 2). The Illumina Human660W revealed that the 'breakpoint' for this region in case 1 is between the STRs D20S887 and D20S902 close to D20S887 at the 20q13.13 band (the last heterozygous SNP was rs6020218 (48 083 796) and the first isodisomic one was rs4811002 (48088 423)), and that in case 4 the breakpoint is between the STRs D20S902 and D20S1044 (the last heterozygous SNP was rs1052653 (49 438 061) and the first isodisomic was rs1569736 (49 439 729); Fig. 4A and B). Considering the patients previously reported with breakpoints in this region, we observed that Aldred et al. (46) described two patients with PHP-Ia in whom deletions were identified at 20q13 (46, XY, del (20) (q13.13q13.32) and 46, XX, del (20) (q13.31q13.33)). The male patient carried a deletion that started near the breakpoint of cases 1 and 4 , therefore this region could be considered a hotspot for homologous recombination for the long arm of chromosome 20.

On the other hand, the microsatellite markers for case 2 revealed the presence of a paternal isodisomy for the whole long arm of chromosome 20 (Table 2). Analysis of the results obtained in the Illumina Human660W confirmed this result (Fig. 4C). The genetic alteration in this patient is similar to the patient reported by Bastepe et al. (30) with pat20qUPD.

Regarding the putative mechanism leading to 20qUPD accompanied by the presence of both 20p homologs derived from both parents, a postzygotic mitotic recombination seems the most probable cause
(Fig. 2). The presence of a pat20qUPD (whole long arm for case 2 and from 20q13.13-qter for cases 1 and 4) suggests that a somatic crossover between the two copies of chromosome $20 \mathrm{q}$ at mitosis, followed by random segregation of sister chromatids in embryoderived cells (from the inner cell mass or later), is likely to have given rise to the segmental pat20qUPD observed in the patients, as described previously (15). Somatic recombination and random segregation can produce different cell types. This mechanism can result in somatic mosaicism, the extent of which will depend on the stage at which the postzygotic recombination event occurred (14). Somatic recombination at a very early stage, followed by a random loss of a particular cell type (in the extra-embryonic tissues, for instance), may be the reason for the lack of mosaicism observed in these patients. It is also possible that a low level of mosaicism in the patients may have gone undetected. The analysis of other tissues might have revealed a degree of mosaicism; however, only lymphocytes were available for the study, and the resulting phenotype strongly suggests that this mosaicism would be present at a low level.

The molecular genetic findings in case 3 (GS0082) indicate that he did not inherit any copy of chromosome 20 from his mother. The microsatellite markers revealed the presence of a paternal heterodisomy for the short arm and a paternal isodisomy for the long arm of chromosome 20 (Table 2). The analysis of the results obtained by the Illumina Human660W array allowed us to identify a small homozygous region in 20p11.21 without informative microsatellite markers and a putative interstitial paternal heterodisomic region at the long arm (20q13.33-20-qter) (Fig. 4D). The $20 q 13.33$ band has only been tested by the microsatellite marker D20S173, which begins at base 58311403 , but the first heterozygous SNPs identified in this patient at rs6101320 is the nucleotide position 59346527 . We also analyzed several extra microsatellite markers at the 20p11.21 (D20S802, D2OS566E, and D2OS589E) and 20q13.33 (Z94413, D2OS1024, D2OS1106, G20531, RH25609, and D2OS127E) bands, but unfortunately they were noninformative, so it is also possible that the distal end of 20 does not have UPD.

The molecular findings could be explained by at least two homologous recombination events of chromosome 20 followed by nondisjunction during meiosis II (secondary heterodisomy) as shown in Fig. 1.

The interstitial deletion described by Aldred et al. (46) in the female patient includes a breakpoint at 20q13.31, coinciding with the position where case 3 has an homologous recombination between parental chromosomes. Therefore, it seems possible that in bands 20q13.13 (for the GS0060 and GS0090 patients) and 20q13.33 (for the GS0082 patient), there are regions of recombination that could lead to the deletions described 


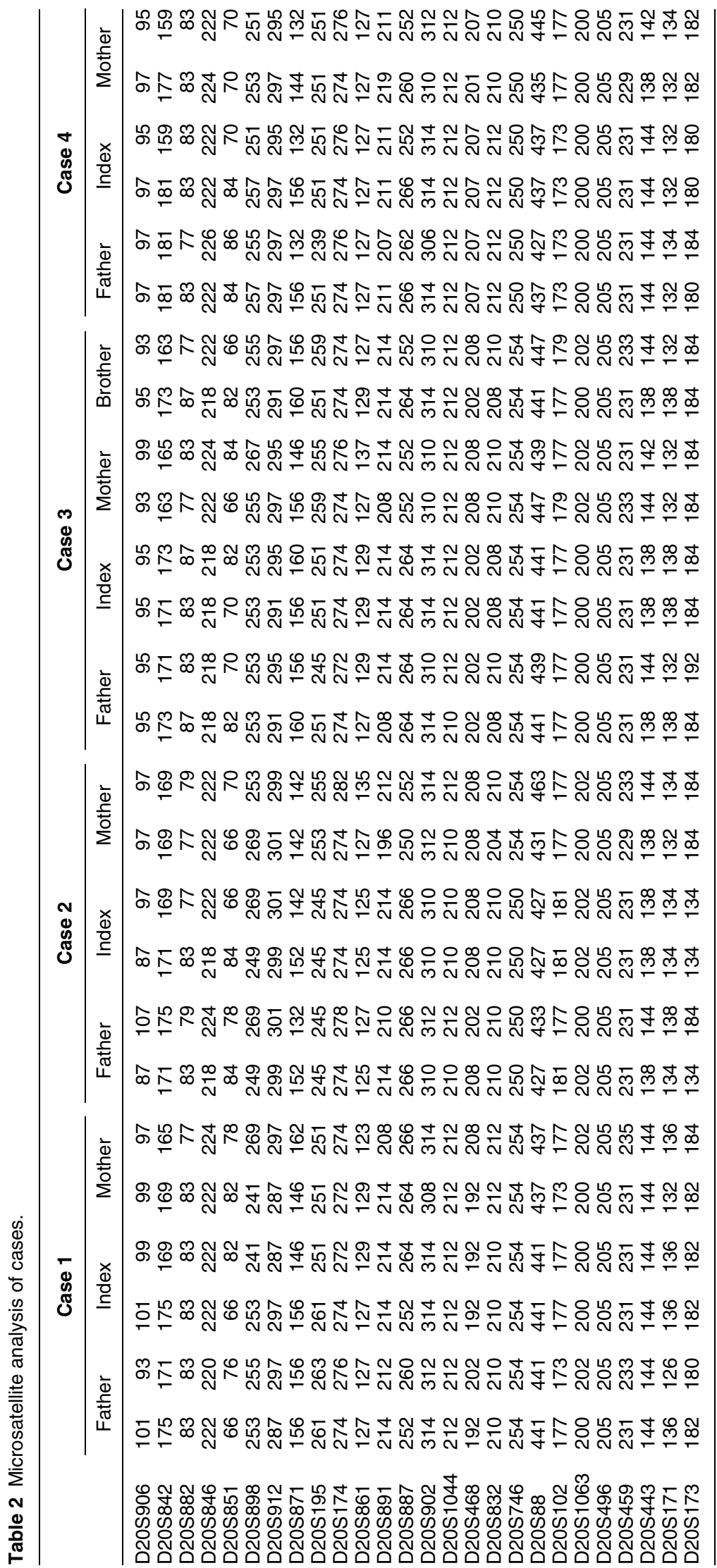


A

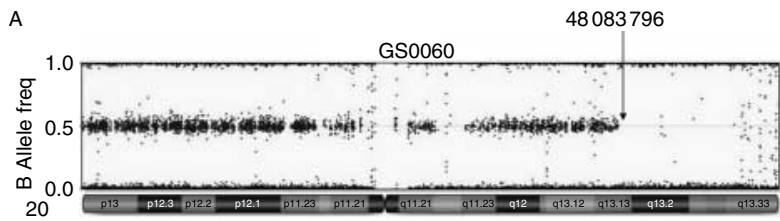

B

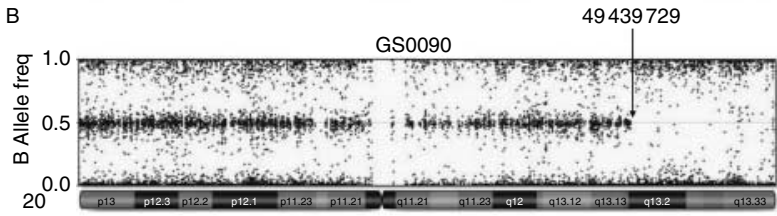

C

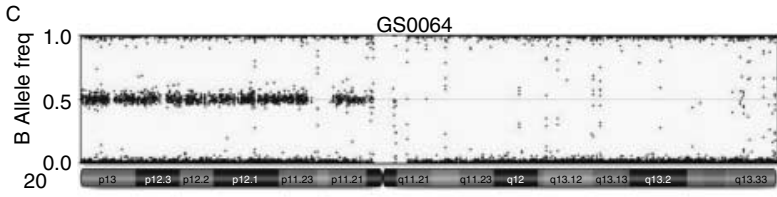

D

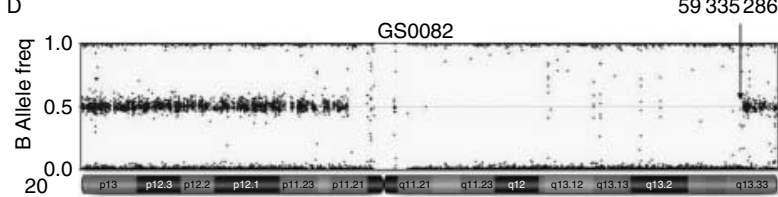

Figure 4 Array-CGH SNP genotyping of the patients analyzed. Chromosome 20 plot of case $1(A)$, case $4(B)$, case $2(C)$, and case $3(D)$. The panels show the homozygous/heterozygous distribution (B allele frequency) for all the SNPs genotyped.

The genomic dosage panel (log $R$ ratio) is not shown as it was normal for all the cases. The gray line in the center of the plot $(0.5)$ represents heterozygosity at particular SNPs. The drastic reduction in heterozygous SNPS denotes the region of UPD. Disomy breakpoints at $20 \mathrm{q}$ are indicated by the arrows with the corresponding nucleotide position.

by Aldred et al. (46) and the partial isodisomies identified in these patients.

With respect to clinical implications, no significant differences were found in pat20qUPD compared with patients with methylation defect at GNAS locus of unknown origin; however, new genotype-phenotype correlations in PHP seem to emerge from our research. We observed that cases with longer pat20qUPDs (cases 2 and 3) were diagnosed with PHP at a younger age (9 and 5 years respectively) than those with shorter UPDs. Similarly, cases 2 and 3 both showed macrocephaly, rounded face, obesity/macrosomy in infancy, in contrast to cases 1 and 4 who lacked these prominent clinical features. Therefore, in our cases, the size of the underlying molecular defect correlated well with individual clinical and biochemical profiles as has been already reported in other imprinting disorders (49). In fact, when we looked at the imprinted genes located at 20q11.2-q13.13 (those which are shared by cases 2 and 3 but not by 1 and 4), we found that some of them could explain the different phenotypes. For example, NNAT, located at 20q11.2-q12 and coding for neuronatin, an imprinted gene actively transcribed only from the paternal allele (50) and whose putative role in human energy homeostasis has been pointed out (51), could explain the macrosomic appearance in the neonatal period of case 3 and the obesity in the infant period of case 2. Besides, it is well known that genes expressed from only one allele are often involved in regulation of growth and hence indirectly in the control of energy and glucose homeostasis (52). However, we should not forget the putative existence of a paternally inherited mutation that is inherited in a recessive manner and manifests as specific phenotype, as reported previously (53). Nevertheless, further cases are needed for specific genotype-phenotype correlations.

In summary, we describe four patients with PHP, out of twenty with methylation defects, who had a partial pat20qUPD involving distal 20q from 20q13.13-qter in two cases and interstitial pat20qUPD in one case. This is the first description of patients with PHP and segmental pat20qUPD. Our findings further highlight the complexity of the genetic basis of PHP and emphasize the importance of using polymorphic markers that map the whole of chromosome 20, as well as the SNPs-based arrays, for molecular diagnosis of UPD20 in PHP.

As the real prevalence of UPD in PHP patients might well be underestimated, we propose to perform a detailed molecular analysis of all patients diagnosed with PHP, including analysis for UPD in those with abnormal imprinting at all GNAS DMRs, and a further comparison of clinical and biochemical profiles of PHP patients with and without UPD, to improve our knowledge of the disease, and to provide patients and families with more accurate prognostic predictions and individualized clinical management and follow-up.

\section{Supplementary data}

This is linked to the online version of the paper at http://dx.doi.org/10. 1530/EJE-10-0435.

\section{Declaration of interest}

The authors declare that there is no conflict of interest that could be perceived as prejudicing the impartiality of the research reported.

\section{Funding}

G Pérez de Nanclares is co-funded by the Instituto de Salud Carlos III I3SNS Program (CP03/0064; SIVI 1395/09). I Garin has received a grant from the Basque Department of Education (BFI06.266). This work was partially funded by grant GV2008/111035 from the Basque Department of Health and BIO08/ER/001. This group is also supported by the Centro de Investigacion Biomedica en Red de Enfermedades Raras (CIBERER - the Spanish Biomedical Network Research Centre on Rare Diseases), ISCIII.

\section{Acknowledgements}

We thank all members of the affected families for their collaborative participation in this study. The authors are very grateful to Dr Francisco Martínez for carefully reading the manuscript and his 
valuable comments and suggestions. The authors will also like to thank Valeria Romanelli for her helpful comments on MS-MLPA interpretation.

Members of the Spanish PHP Group: Complejo Hospitalario de Cáceres, Cáceres (J Arroyo); Complejo Hospitalario Dr Negrin, Las Palmas de Gran Canaria (F Sáez, A Sánchez); Complejo Hospitalario Materno Insular, Las Palmas de Gran Canaria (A Domínguez, A Santana); Complejo Hospitalario Universitario de Albacete, Albacete (R Ruiz); Complexo Hospitalario Universitario Santiago de Compostela, A Coruña (L Castro); Hospital Central de Asturias, Asturias (C Rivas); Hospital Clínico San Carlos, Madrid (O Pérez); Hospital de Barbanza, A Coruña (S Molinos), Hospital de Cruces, Bizkaia (S Gaztambide, M D Moure, A Vela); Hospital de Donostia, Gipuzkoa (R Saez, G Unanue); Hospital de Navarra, Navarra (E Menéndez, A Anda); Hospital de Nens, Barcelona (C Pavia); Hospital de Txagorritxu, Álava (I DiezLopez); Hospital del Mar, Barcelona (M Bonet); Hospital Do Meixoeiro, Vigo (M J Morales); Hospital General de Alicante, Alicante (M Zapico); Hospital General de Ciudad Real, Ciudad Real (M Aguirre); Hospital Infantil Universitario del Niño Jesús, Madrid (M T Muñoz, O RubioCabezas, J Argente); Hospital Infantil Vall D’Hebron, Barcelona (L Audi, D Yeste); Hospital Materno Infantil Carlos Haya, Málaga (F Soriguer); Hospital Príncipe de Viana, Navarra (M García, R M Rodríguez, M J Goñi); Hospital Puerta del Mar; Cádiz (D Armenta, D Gonzalez-Duarte); Hospital Ramón y Cajal, Madrid (R Barrio); Hospital San Jorge, Huesca (A Cámara); Hospital Sant Joan de Déu, Barcelona (L Martorell, L Suárez, R Cardona, E Gean); Hospital Severo Ochoa, Madrid (B García-Cuartero); Hospital Teresa de Herrera, A Coruña (M S Pereira, B Rodríguez); Hospital Universitario 12 de Octubre, Madrid (S Azriel); Hospital Universitario de Guadalajara, Guadalajara (J M Jiménez, L Sentchordi); Hospital Universitario de Valme, Sevilla (R Espino-Aguilar); Hospital Universitario La Fe, Valencia (M Beneyto); Hospital Universitario La Paz, Madrid (C Álvarez, B Lecumberri); Hospital Universitario Marques de Valdecilla, Cantabria (C Luzuriaga); Hospital Universitario Miguel Servet, Zaragoza (M T Calvo, J I Labarta); Hospital Universitario Príncipe de Asturias, Madrid (P Saavedra); Hospital Universitario Reina Sofía, Córdoba (R Cañete Estrada); Hospital Universitario San Cecilio, Granada (R Orduña); Hospital Universitario Virgen de la Arriaxaca, Murcia (E Guillen-Navarro, C Guillen, F Goñi); Hospital Universitario Virgen del Rocío, Sevilla (J Del Valle); Hospital Virgen de la Salud, Toledo (I Luque, A Menéndez); Hospital Virgen del Camino, Navarra (M Oyarzabal).

\section{References}

1 Engel E. A new genetic concept: uniparental disomy and its potential effect, isodisomy. American Journal of Medical Genetics 19806 137-143. (doi:10.1002/ajmg.1320060207)

2 Kotzot D. Abnormal phenotypes in uniparental disomy (UPD): fundamental aspects and a critical review with bibliography of UPD other than 15. American Journal of Medical Genetics 1999 82 265-274. (doi:10.1002/(SICI)1096-8628(19990129)82:3< 265::AID-AJMG14>3.0.CO;2-6)

3 Robinson WP. Mechanisms leading to uniparental disomy and their clinical consequences. BioEssays 200022 452-459. (doi:10.1002/(SICI)1521-1878(200005)22:5 <452::AID-BIE S7> 3.0.CO;2-K)

4 Engel E. A fascination with chromosome rescue in uniparental disomy: Mendelian recessive outlaws and imprinting copyrights infringements. European Journal of Human Genetics 2006 14 1158-1169. (doi:10.1038/sj.ejhg.5201619)

5 Engel E. Uniparental disomy revisited: the first twelve years. American Journal of Medical Genetics 199346 670-674. (doi:10. 1002/ajmg.1320460613)

6 Ledbetter DH \& Engel E. Uniparental disomy in humans: development of an imprinting map and its implications for prenatal diagnosis. Human Molecular Genetics 19954 1757-1764.
7 Field LL, Tobias R, Robinson WP, Paisey R \& Bain S. Maternal uniparental disomy of chromosome 1 with no apparent phenotypic effects. American Journal of Human Genetics 199863 1216-1220. (doi:10.1086/302050)

8 Cassidy SB \& Schwartz S. Prader-Willi and Angelman syndromes. Disorders of genomic imprinting. Medicine 199877 140-151. (doi:10.1097/00005792-199803000-00005)

9 Eggermann T, Marg W, Mergenthaler S, Eggermann K, Schemmel V, Stoffers U, Zerres K \& Spranger S. Origin of uniparental disomy 6: presentation of a new case and review on the literature. Annales de Genetique 200144 41-45. (doi:10.1016/ S0003-3995(01)01035-8)

10 Kotzot D. Maternal uniparental disomy 14 dissection of the phenotype with respect to rare autosomal recessively inherited traits, trisomy mosaicism, and genomic imprinting. Annales de Genetique 200447 251-260. (doi:10.1016/j.anngen.2004.03. 006)

11 Sutton VR \& Shaffer LG. Search for imprinted regions on chromosome 14: comparison of maternal and paternal UPD cases with cases of chromosome 14 deletion. American Journal of Medical Genetics 200093 381-387. (doi:10.1002/ 1096-8628(20000828)93:5<381::AID-AJMG7 > 3.0.CO;2-9)

12 Rossignol S, Netchine I, Le Bouc Y \& Gicquel C. Epigenetics in Silver-Russell syndrome. Best Practice and Research. Clinical Endocrinology and Metabolism 200822 403-414. (doi:10.1016/ j.beem.2008.01.012)

13 Henry I, Puech A, Riesewijk A, Ahnine L, Mannens M, Beldjord C, Bitoun P, Tournade MF, Landrieu P \& Junien C. Somatic mosaicism for partial paternal isodisomy in Wiedemann-Beckwith syndrome: a post-fertilization event. European Journal of Human Genetics 1993 1 19-29.

14 Kotzot D. Complex and segmental uniparental disomy updated. Journal of Medical Genetics 200845 545-556. (doi:10.1136/jmg. 2008.058016)

15 Kotzot D. Complex and segmental uniparental disomy (UPD): review and lessons from rare chromosomal complements. Journal of Medical Genetics 200138 497-507. (doi:10.1136/ jmg.38.8.497)

16 Kinard RE, Walton JE \& Buckwalter JA. Pseudohypoparathyroidism: report on a family with four affected sisters. Archives of Internal Medicine 1979139 204-207. (doi:10.1001/archinte. 139.2.204)

17 Albright F, Burnett CH, Smith PH \& Parson W. Pseudohypoparathyroidsm - an example of "Seabright syndrome". Endocrinology 194230 922-932.

18 Weinstein LS. In G Proteins, Receptors and Disease, pp 23-56. Ed. AM Spiegel. New Jersey, 1998.

19 Patten JL, Johns DR, Valle D, Eil C, Gruppuso PA, Steele G, Smallwood PM \& Levine MA. Mutation in the gene encoding the stimulatory G protein of adenylate cyclase in Albright's hereditary osteodystrophy. New England Journal of Medicine 1990 322 1412-1419. (doi:10.1056/NEJM199005173222002)

20 Wilson LC, Oude Luttikhuis ME, Clayton PT, Fraser WD \& Trembath RC. Parental origin of $\mathrm{G}_{\mathrm{s}} \alpha$ gene mutations in Albright's hereditary osteodystrophy. Journal of Medical Genetics 199431 835-839. (doi:10.1136/jmg.31.11.835)

21 Weinstein LS, Yu S, Warner DR \& Liu J. Endocrine manifestations of stimulatory $\mathrm{G}$ protein $\alpha$-subunit mutations and the role of genomic imprinting. Endocrine Reviews 200122 675-705. (doi:10.1210/er.22.5.675)

22 Yu LS, Yu D, Lee E, Eckhaus M, Lee R, Corria Z, Accili D, Westphal H \& Weinstein LS. Variable and tissue-specific hormone resistance in heterotrimeric $\mathrm{G}_{\mathrm{s}}$ protein $\alpha$-subunit $\left(\mathrm{G}_{\mathrm{s}} \alpha\right)$ knockout mice is due to tissue-specific imprinting of the gs $\alpha$ gene. PNAS 199895 8715-8720. (doi:10.1073/pnas.95.15.8715)

23 Bastepe M. The GNAS locus and pseudohypoparathyroidism. Advances in Experimental Medicine and Biology $200862627-40$.

24 Levine MA. In Endocrinology, pp 1133-1153. Eds LJ De Groot \& J Jameson. Philadelphia: W.B. Saunders, 2000. 
25 Liu J, Litman D, Rosenberg MJ, Yu S, Biesecker LG \& Weinstein LS. A GNAS1 imprinting defect in pseudohypoparathyroidism type IB. Journal of Clinical Investigation 2000106 1167-1174. (doi:10. 1172/JCI10431)

26 Bastepe M, Pincus JE, Sugimoto T, Tojo K, Kanatani M, Azuma Y, Kruse K, Rosenbloom AL, Koshiyama H \& Juppner H. Positional dissociation between the genetic mutation responsible for pseudohypoparathyroidism type Ib and the associated methylation defect at exon A/B: evidence for a long-range regulatory element within the imprinted GNAS1 locus. Human Molecular Genetics 200110 1231-1241. (doi:10.1093/hmg/10.12.1231)

27 Bastepe M, Frohlich LF, Hendy GN, Indridason OS, Josse RG, Koshiyama H, Korkko J, Nakamoto JM, Rosenbloom AL, Slyper AH, Sugimoto T, Tsatsoulis A, Crawford JD \& Juppner H. Autosomal dominant pseudohypoparathyroidism type $\mathrm{Ib}$ is associated with a heterozygous microdeletion that likely disrupts a putative imprinting control element of GNAS. Journal of Clinical Investigation 2003112 1255-1263. (doi:10.1172/JCI19159)

28 Linglart A, Gensure RC, Olney RC, Juppner H \& Bastepe M. A novel STX16 deletion in autosomal dominant pseudohypoparathyroidism type $\mathrm{Ib}$ redefines the boundaries of a cis-acting imprinting control element of GNAS. American Journal of Human Genetics 200576 804-814. (doi:10.1086/429932)

29 Bastepe M, Frohlich LF, Linglart A, Abu-Zahra HS, Tojo K, Ward LM \& Juppner H. Deletion of the NESP55 differentially methylated region causes loss of maternal GNAS imprints and pseudohypoparathyroidism type Ib. Nature Genetics 200537 25-27. (doi:10.1038/ng1560)

30 Bastepe M, Lane AH \& Juppner H. Paternal uniparental isodisomy of chromosome 20q - and the resulting changes in GNAS1 methylation - as a plausible cause of pseudohypoparathyroidism. American Journal of Human Genetics 200168 1283-1289. (doi:10. 1086/320117)

31 Lecumberri B \& Fernandez-Rebollo E. Coexistence of two different pseudohypoparathyroidism subtypes ( $\mathrm{Ia}$ and $\mathrm{Ib}$ ) in the same kindred with independent $\mathrm{G}_{\mathrm{s}} \alpha$ coding mutations and GNAS imprinting defects. Journal of Medical Genetics 201047 276-280. (doi:10.1136/jmg.2009.071001)

32 de Nanclares GP, Fernandez-Rebollo E, Santin I, GarciaCuartero B, Gaztambide S, Menendez E, Morales MJ, Pombo M, Bilbao JR, Barros F, Zazo N, Ahrens W, Juppner H, Hiort O, Castano L \& Bastepe M. Epigenetic defects of GNAS in patients with pseudohypoparathyroidism and mild features of Albright's hereditary osteodystrophy. Journal of Clinical Endocrinology and Metabolism 200792 2370-2373. (doi:10.1210/jc.2006-2287)

33 Simon-Sanchez J, Scholz S, Fung HC, Matarin M, Hernandez D, Gibbs JR, Britton A, de Vrieze FW, Peckham E, Gwinn-Hardy K, Crawley A, Keen JC, Nash J, Borgaonkar D, Hardy J \& Singleton A. Genome-wide SNP assay reveals structural genomic variation, extended homozygosity and cell-line induced alterations in normal individuals. Human Molecular Genetics 200716 1-14. (doi:10.1093/hmg/ddl436)

34 Spence JE, Perciaccante RG, Greig GM, Willard HF, Ledbetter DH, Hejtmancik JF, Pollack MS, O'Brien WE \& Beaudet AL. Uniparental disomy as a mechanism for human genetic disease. American Journal of Human Genetics 198842 217-226.

35 Henry I, Bonaiti-Pellie C, Chehensse V, Beldjord C, Schwartz C, Utermann G \& Junien C. Uniparental paternal disomy in a genetic cancer-predisposing syndrome. Nature 1991351 665-667. (doi:10.1038/351665a0)

36 Nicholls RD, Pai GS, Gottlieb W \& Cantu ES. Paternal uniparental disomy of chromosome 15 in a child with Angelman syndrome. Annals of Neurology 199232 512-518. (doi:10.1002/ana. 410320406)

37 Kotzot D, Schmitt S, Bernasconi F, Robinson WP, Lurie IW, Ilyina $\mathrm{H}$, Méhes $\mathrm{K}$, Hamel $\mathrm{BC}$, Otten BJ, Hergersberg $\mathrm{M}$, Werder E, Schoenle E \& Schinzel A. Uniparental disomy 7 in Silver-Russell syndrome and primordial growth retardation. Human Molecular Genetics 19954 583-587. (doi:10.1093/ $\mathrm{hmg} / 4.4 .583)$
38 Robinson WP, Bottani A, Xie YG, Balakrishman J, Binkert F, Machler M, Prader A \& Schinzel A. Molecular, cytogenetic, and clinical investigations of Prader-Willi syndrome patients. American Journal of Human Genetics 199149 1219-1234.

39 Gardner RJ, Robinson DO, Lamont L, Shield JP \& Temple IK. Paternal uniparental disomy of chromosome 6 and transient neonatal diabetes mellitus. Clinical Genetics 199854 522-525. (doi:10.1111/j.1399-0004.1998.tb03774.x)

40 Cotter PD, Kaffe S, McCurdy LD, Jhaveri M, Willner JP \& Hirschhorn K. Paternal uniparental disomy for chromosome 14: a case report and review. American Journal of Medical Genetics 1997 70 74-79. (doi:10.1002/(SICI)1096-8628(19970502)70:1< 74::AID-AJMG14>3.0.CO;2-U)

41 Chudoba I, Franke Y, Senger G, Sauerbrei G, Demuth S, Beensen V, Neumann A, Hansmann I \& Claussen U. Maternal UPD 20 in a hyperactive child with severe growth retardation. European Journal of Human Genetics 19997 533-540. (doi:10.1038/sj.ejhg. 5200287)

42 Eggermann T, Mergenthaler S, Eggermann K, Albers A, Linnemann K, Fusch C, Ranke MB \& Wollmann HA. Identification of interstitial maternal uniparental disomy (UPD) (14) and complete maternal UPD (20) in a cohort of growth retarded patients. Journal of Medical Genetics 200138 86-89. (doi:10. 1136/jmg.38.2.86)

43 Salafsky IS, MacGregor SN, Claussen U \& von Eggeling F. Maternal UPD20 in an infant from a pregnancy with mosaic trisomy 20. Prenatal Diagnosis 200121 860-863. (doi:10.1002/ pd.158)

44 Velissariou V, Antoniadi T, Gyftodimou J, Bakou K, Grigoriadou M, Christopoulou S, Hatzipouliou A, Donoghue J, Karatzis P, Katsarou E \& Petersen MB. Maternal uniparental isodisomy 20 in a foetus with trisomy 20 mosaicism: clinical, cytogenetic and molecular analysis. European Journal of Human Genetics 200210 694-698. (doi:10.1038/sj.ejhg.5200867)

45 Venditti CP, Hunt P, Donnenfeld A, Zackai E \& Spinner NB. Mosaic paternal uniparental (iso)disomy for chromosome 20 associated with multiple anomalies. American Journal of Medical Genetics. Part A 2004 124A 274-279. (doi:10.1002/ajmg.a. 20430)

46 Aldred MA, Aftimos S, Hall C, Waters KS, Thakker RV, Trembath RC \& Brueton L. Constitutional deletion of chromosome 20q in two patients affected with albright hereditary osteodystrophy. American Journal of Medical Genetics 2002113 167-172. (doi:10.1002/ajmg.10751)

47 Hsu LY, Kaffe S \& Perlis TE. A revisit of trisomy 20 mosaicism in prenatal diagnosis - an overview of 103 cases. Prenatal Diagnosis 199111 7-15. (doi:10.1002/pd.1970110103)

48 Wallerstein R, Yu MT, Neu RL, Benn P, Lee BC, Crandall B, Disteche C, Donahue R, Harrison B, Hershey D, Higgins RR, Jenkins LS, Jackson-Cook C, Keitges E, Khodr G, Lin CC, Luthardt FW, Meisner L, Mengden G, Patil SR, Rodriguez M, Sciorra LJ, Shaffer LG, Stetten G, Van Dyke DL \& Wang H. Common trisomy mosaicism diagnosed in amniocytes involving chromosomes 13, 18, 20 and 21: karyotype-phenotype correlations. Prenatal Diagnosis 200020 103-122. (doi:10.1002/ (SICI)1097-0223(200002)20:2<103::AID-PD761>3.0.CO;2-K)

49 Bruce S, Hannula-Jouppi K, Peltonen J, Kere J \& LipsanenNyman M. Clinically distinct epigenetic subgroups in SilverRussell syndrome: the degree of H19 hypomethylation associates with phenotype severity and genital and skeletal anomalies. Journal of Clinical Endocrinology and Metabolism 2009 94 579-587. (doi:10.1210/jc.2008-1805)

50 Evans HK, Wylie AA, Murphy SK \& Jirtle RL. The neuronatin gene resides in a "micro-imprinted" domain on human chromosome 20q11.2. Genomics 200177 99-104. (doi:10.1006/geno.2001. 6612)

51 Vrang N, Meyre D, Froguel P, Jelsing J, Tang-Christensen M, Vatin V, Mikkelsen JD, Thirstrup K, Larsen LK, Cullberg KB, Fahrenkrug J, Jacobson P, Sjostrom L, Carlsson LM, Liu Y, 
Liu X, Deng HW \& Larsen PJ. The imprinted gene neuronatin is regulated by metabolic status and associated with obesity. Obesity 201018 1289-1296. (doi:10.1038/oby.2009.361)

52 Plagge A, Gordon E, Dean W, Boiani R, Cinti S, Peters J \& Kelsey G. The imprinted signaling protein $\mathrm{XL}$ alpha $\mathrm{s}$ is required for postnatal adaptation to feeding. Nature Genetics 200436 818-826. (doi:10.1038/ng1397)

53 Ferrer-Bolufer I, Dalmau J, Quiroga R, Oltra S, Orellana C, Monfort S, Rosello M, De La Osa A \& Martinez F. Tyrosinemia type 1 and Angelman syndrome due to paternal uniparental isodisomy 15. Journal of Inherited Metabolic Disease, 2009. (doi:10. 1007/s10545-009-9014-9)
54 Rivolta C, Berson EL \& Dryja TP. Paternal uniparental heterodisomy with partial isodisomy of chromosome 1 in a patient with retinitis pigmentosa without hearing loss and a missense mutation in the Usher syndrome type II gene USH2A. Archives of Ophthalmology 2002120 1566-1571.

Received 7 September 2010

Accepted 13 September 2010 